\title{
BMJ Open Evaluating a custom-designed aid to improve communication of genetic results in families with hypertrophic cardiomyopathy: study protocol for a randomised controlled trial
}

Charlotte Burns, ${ }^{1,2,3}$ Laura Yeates, ${ }^{1,3}$ Christopher Semsarian, ${ }^{1,2,3}$ Jodie Ingles ${ }^{1,2,3}$

To cite: Burns C, Yeates L, Semsarian C, et al. Evaluating a custom-designed aid to improve communication of genetic results in families with hypertrophic cardiomyopathy: study protocol for a randomised controlled trial. BMJ Open 2019;9:e026627. doi:10.1136/ bmjopen-2018-026627

- Prepublication history and additional material for this paper are available online. To view these files, please visit the journal online (http://dx.doi. org/10.1136/bmjopen-2018026627).

Received 12 September 2018 Revised 6 December 2018 Accepted 10 December 2018

D) Check for updates

C Author(s) (or their employer(s)) 2019. Re-use permitted under CC BY-NC. No commercial re-use. See rights and permissions. Published by BMJ.

${ }^{1}$ Agnes Ginges Centre for Molecular Cardiology at Centenary Institute, The University of Sydney, Newtown, NSW, Australia

${ }^{2}$ Faculty of Medicine and Health, The University of Sydney, Newtown, NSW, Australia ${ }^{3}$ Department of Cardiology, Royal Prince Alfred Hospital, Sydney, NSW, Australia

Correspondence to

Dr Jodie Ingles;

j.ingles@centenary.org.au

\section{ABSTRACT}

Introduction Genetic testing for hypertrophic cardiomyopathy ( $\mathrm{HCM})$ in the era of genomics brings unique challenges for genetic counselling. The number of genes routinely included in an HCM gene panel has increased markedly, many with minimal if any robust evidence of gene-disease association. Subsequently, there is a greater chance of uncertain genetic findings. The responsibility of communicating this information with atrisk relatives lies with the index case (proband). We have developed a communication aid to assist with the delivery of genetic results to the proband. We have previously shown the aid is feasible and acceptable and have now developed a study protocol for a randomised controlled trial of a genetic counsellor-led intervention incorporating the communication aid.

Methods and analysis This is a prospective randomised controlled trial. We will investigate the impact of a genetic counsellor-led intervention to return proband genetic results using a custom-designed communication aid. We aim to improve knowledge and empowerment. The primary outcome of this trial is the ability and confidence of the proband to communicate genetic results to atrisk relatives. Secondary outcomes will assess genetic knowledge, satisfaction with services, outcomes from genetic counselling and psychological adaptation to genetic information.

Ethics and dissemination This study has been approved by and is in strict accordance with the Sydney Local Health District Ethics Review Committee (X16-0030; 22/01/2016; version 1). Results from this trial will be prepared as a manuscript and submitted to peer-reviewed journals for publication as well as submission for presentation at national and international meetings.

Trial registration number ACTRN12617000706370.

\section{INTRODUCTION}

\section{Background and rationale}

Genetic testing in the era of genomics brings unique challenges for the genetic counselling of families. Hypertrophic cardiomyopathy (HCM) is a clinically heterogeneous inherited heart disease characterised by
Strengths and limitations of this study

- This study will assess the effectiveness of a communication aid to improve the ability and confidence of patients with hypertrophic cardiomyopathy (HCM) to communicate genetic test results with their atrisk relatives.

- The results of this trial will inform genetic counselling practice for HCM genetic testing, as well as be broadly applicable for other inherited heart diseases.

- Limitations include the generalisability of our findings, which are true for a specialised multidisciplinary clinic where the intervention was performed but may not be representative of the broader HCM population undergoing genetic testing.

- As genomic technologies continue to evolve, uncertainty and complexity of genetic findings will likely increase over time.

unexplained left ventricular hypertrophy in the absence of a loading condition such as hypertension. ${ }^{1}$ With a prevalence of 1 in 200-500, it is one of the most common inherited heart diseases and clinical manifestations can range from asymptomatic through to heart failure or sudden cardiac death. ${ }^{2}$ In the setting of HCM, genetic testing of the index case (proband) can provide invaluable information by allowing at-risk relatives the opportunity to undergo cascade genetic testing to look for the presence or absence of the family-specific variants. ${ }^{3}$ The first step is often the most challenging, requiring identification of a variant for which there is sufficient evidence of causation.

Genetic counselling is a critical aspect of the process for genetic testing and for understanding inheritance risks, characterisation of the family history, and emotional support. ${ }^{4}$ Within a clinical setting, pretest and post-test genetic counselling should include discussion 
of inheritance risks and clinical screening guidelines for at-risk relatives. ${ }^{5}$ This allows asymptomatic at-risk relatives to make proactive, informed decisions regarding their risk, including family planning decisions.

How a patient understands and communicates this genetic information to their at-risk relatives is critical to ensuring patients' get the most value out of genetic testing. This task of communication relies on the proband within the family. Current Australian practice and privacy laws dictate that in most cases the healthcare provider does not make contact with relatives to disclose risk information. Therefore, it follows that in order to communicate genetic results or risk information, the proband must have adequate understanding of the information they have received from their healthcare provider. Several studies indicate this may be problematic, and some individuals may not retain or understand the information presented to them. ${ }^{6}$

\section{Existing knowledge}

Currently, literature estimates between $20 \%$ and $40 \%$ of relatives remain unaware of relevant genetic information and do not act on information even when they have reportedly been informed of their risk. ${ }^{7-9}$ Many factors have been identified that influence family communication about genetic risk, including complicated family dynamics, guilt, anxiety and gender; however, these factors are difficult to target as areas for improvement within the context of one or two genetic counselling sessions. ${ }^{781011}$ There are stages within the genetic counselling process, where communication of genetic results and uptake of appropriate screening may be influenced.

Our group and others have shown some of the barriers that can negatively impact on family communication. In a qualitative study of patients with HCM undergoing comprehensive genetic testing, many patients reported uncertain results to be conveyed less among families. ${ }^{12}$ Furthermore, these results are often misunderstood. For example, among this cohort, probands with uncertain results perceived these results as falsely reassuring or conversely suggests their disease is 'worse' or 'different'. This led to a misunderstanding that their result was not heritable, and therefore, communication with relatives did not occur. ${ }^{12}$ Supporting these findings, the general genetics literature highlights that risk perception and understanding of results, though varied, can be poor, inaccurate and incomplete. ${ }^{13} 14$

There is evidence for the effectiveness of a genetic counsellor in addressing some of the communication and knowledge barriers. ${ }^{15-17}$ One key area for intervention is during the post-test genetic counselling session. Genetic and risk information can be difficult to understand and explain clearly and as a consequence, the patient may not gain sufficient knowledge and lack confidence to convey these key messages to at-risk relatives. ${ }^{12}$ Furthermore, it has been shown that patients deliberate on the appropriate time to communicate genetic information and make their own decisions regarding which relatives they will inform, regardless of the recommendation of professionals. ${ }^{71819}$ Few resources exist that aim to facilitate effective communication to at-risk relatives. We therefore hypothesise that improving knowledge of an HCM genetic diagnosis will have a positive impact on communication to at-risk relatives, as well as genetic knowledge, satisfaction with services, outcomes from genetic counselling and psychological adaptation to genetic information.

\section{Utility of a communication aid}

When asked about family communication, most patients report families should communicate risk among

\section{Table 1 Trial registration data}

\section{Primary registry}

and trial identifying Australian New Zealand Clinical Trials number

\section{Registry: ACTRN12617000706370}

Date of registration in 17/05/2017 primary registry

Secondary identifying NA

numbers

Source(s) of monetary National Heart Foundation of Australia or material support

Primary sponsor The University of Sydney

$\begin{array}{ll}\text { Secondary sponsor } & \text { NA } \\ \text { Contact for public } & \text { Dr Jodie Ingles } \\ \text { queries } & \text { j.ingles@centenary.org.au }\end{array}$

$\begin{array}{ll}\text { Contact for scientific } & \text { Dr Jodie Ingles } \\ \text { queries } & \text { j.ingles@centenary.org.au }\end{array}$

Public title j.ingles@centenary.org.au

of genetic risk information to families with
hypertrophic cardiomyopathy (HCM)

$\begin{array}{ll}\text { Scientific title } & \begin{array}{l}\text { Use of a custom designed aid to improve } \\ \text { communication of genetic results in families } \\ \text { with HCM }\end{array} \\ \begin{array}{l}\text { Countries of } \\ \text { recruitment }\end{array} & \text { Australia }\end{array}$

Health condition (s) or HCM problem (s) studied

Intervention Use of a custom designed aid to communicate HCM genetic test results

\begin{tabular}{|c|c|}
\hline $\begin{array}{l}\text { Key inclusion and } \\
\text { exclusion criteria }\end{array}$ & $\begin{array}{l}\text { HCM probands with a genetic result ready } \\
\text { for return. } \\
\text { Participants must be aged } 18 \text { years or older. } \\
\text { Sufficient written English skills as nominated } \\
\text { by the participant. }\end{array}$ \\
\hline Study type & Prospective randomised controlled trial \\
\hline $\begin{array}{l}\text { Date of first } \\
\text { enrolment }\end{array}$ & 25 November 2016 \\
\hline Target sample size & 45 \\
\hline Recruitment status & Recruiting \\
\hline Primary outcome (s) & $\begin{array}{l}\text { Ability and confidence of the proband to } \\
\text { communicate genetic results to at-risk } \\
\text { relatives. }\end{array}$ \\
\hline $\begin{array}{l}\text { Key secondary } \\
\text { outcomes }\end{array}$ & $\begin{array}{l}\text { Secondary outcomes will assess genetic } \\
\text { knowledge, satisfaction with services, } \\
\text { outcomes from genetic counselling and } \\
\text { psychological adaptation to genetic } \\
\text { information. }\end{array}$ \\
\hline
\end{tabular}




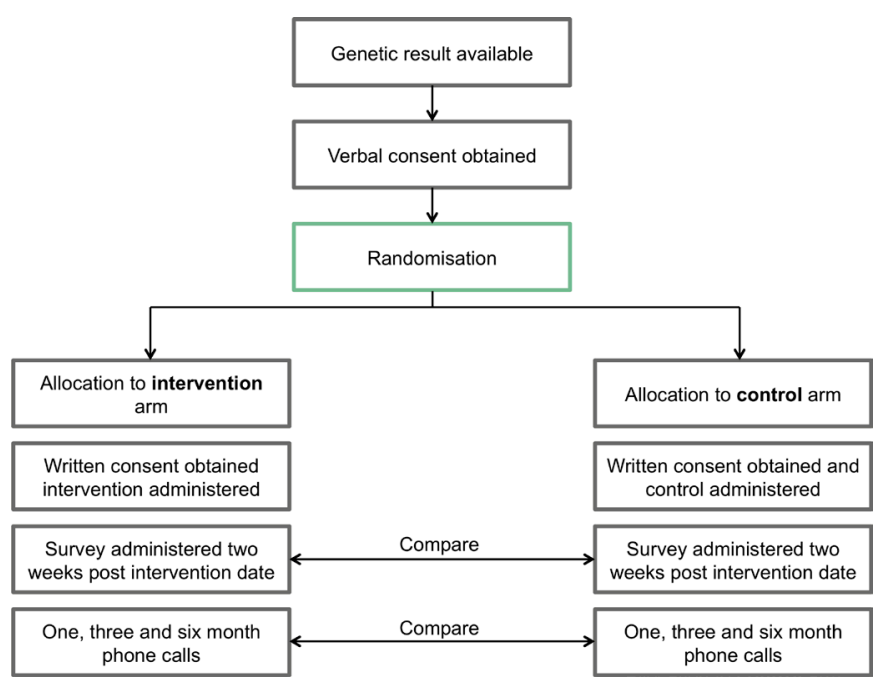

Figure 1 Flow chart of overall study design.

themselves with varying levels of support from their healthcare providers. ${ }^{141720}$ In addition, there is evidence for the effectiveness of genetic counselling to assist with this process. ${ }^{151620}$ Hodgson $e t a l^{21}$ published a randomised controlled trial assessing the impact of a genetic counselling phone intervention on communication of genetic information within families. They found no significant difference between the intervention and control group when measuring contact with genetic services, though in subanalyses of the high-risk children group, the primary outcome was significantly improved. Importantly, the primary outcome measure was contact with a genetic service, which can be difficult to ascertain and may not be the most accurate measure of effectiveness or a direct reflection of communication efforts.

Resources such as decision and communication aids, or family letters, may provide additional support to this process, though more data are needed regarding efficacy. ${ }^{15} 192122$ Decision or communication aids are tools specifically designed to support patients with decision making and unmet information needs. There is evidence for the effectiveness of an aid with regard to improved knowledge and accuracy of risk perceptions. ${ }^{23-25}$ Furthermore, most health information is provided in a written format, which may not be the most effective health communication method. Communication and decision aids provide a format to include visual elements that may improve comprehension, recall and comfort with the information, particularly when health literacy may be an issue.

\section{Need for a trial}

Overall, the literature highlights that probands require additional support to understand and communicate genetic results. The rationale for this study is the critical gap in supporting patients' comprehension and consequent communication of genetic risk to at-risk relatives. Though genetic counsellors are specifically trained in delivering genetic information, information

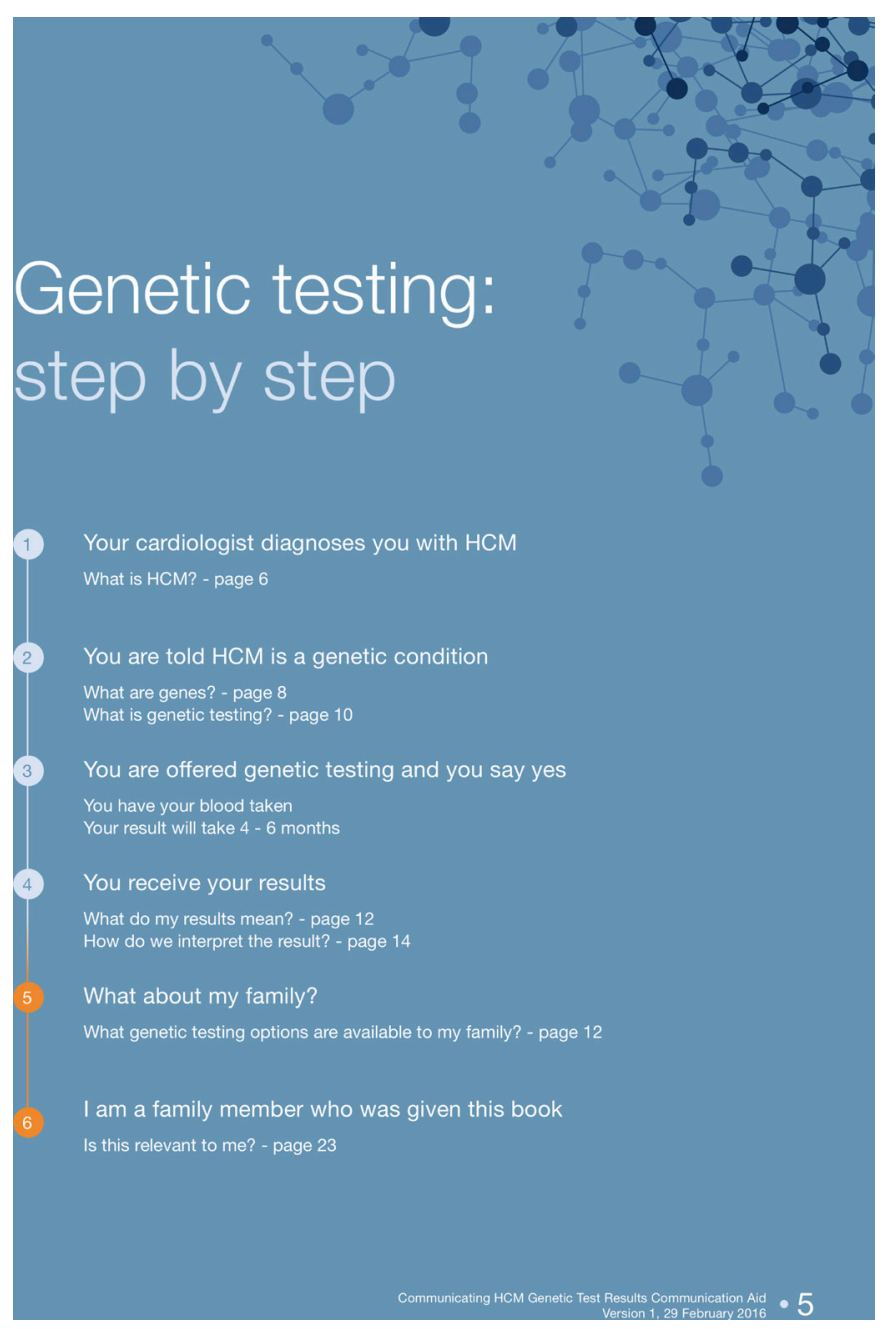

Figure 2 Example page from communication aid: genetic testing step by step. HCM, hypertrophic cardiomyopathy.

needs of patients are not always met and communication among at-risk relatives can be suboptimal. As genetic test results become increasingly complex, an evidence-based approach to supporting patients with genetic knowledge and risk communication should be explored.

\section{Study aims and outcomes}

The aim of this randomised controlled trial is to determine if a genetic counsellor-led intervention using a communication aid for the delivery of HCM genetic test results improves the ability and confidence of the proband to communicate genetic results to at-risk relatives compared with current clinical practice.

1. The primary outcome is the ability and confidence of the proband to communicate genetic results to at-risk relatives, measured at 2 weeks postintervention.

2. Secondary outcomes will assess genetic knowledge, satisfaction with services, patient reported outcomes of genetic counselling and psychological adaptation to genetic information, measured at 2 weeks postintervention.

3. As a longer term outcome, we will systematically assess and document family communication as reported 


\section{What is my genetic result?}

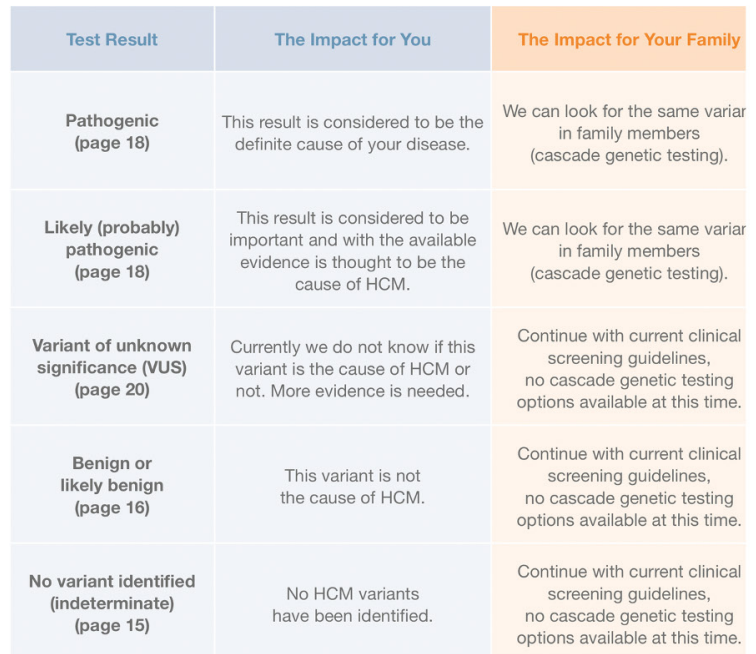

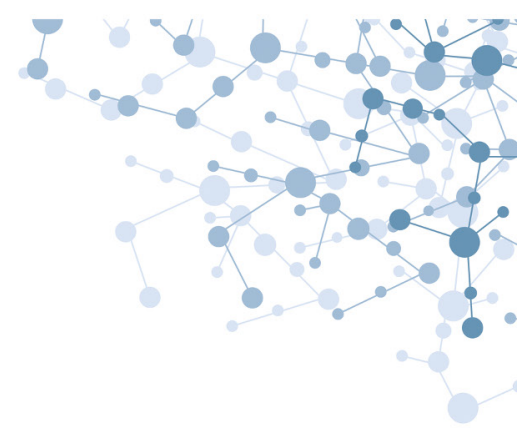

How certain are we that a variant is the cause of HCM?

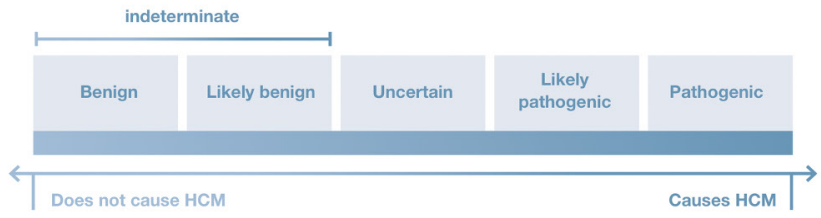

Figure 3 Example page from communication aid: what is my genetic result?

by the proband measured by phone calls at 1, 3 and 6 monthly intervals. The researcher conducting these phone calls will not be blinded to the treatment arm of the participant. During these phone calls, a series of questions regarding family communication and uptake of family screening will be asked of the proband. These phone calls will be conducted and analysed after collection of the primary and secondary outcomes data. This is to prevent interference with results because the phone calls themselves may serve as a family communication intervention. A phone script to be used as a guide for these phone calls is available in the online supplementary material.

\section{METHODS AND ANALYSIS Trial design}

This is a prospective randomised controlled trial. The protocol is reported in accordance with the Standard Protocol Items: Recommendations for Interventional Trials statement, which provides recommendations for a minimum set of scientific, ethical and administrative elements that should be addressed within a clinical trial protocol. ${ }^{26}$ All items from the WHO Trial Registration Data Set are listed in table 1. Consecutive patients with HCM will be invited to participate when they are notified on the phone that their genetic result is ready to be returned. Once written consent is obtained, they will be randomised to receive their genetic result via the intervention or control arm of the study (figure 1).

\section{Study setting}

This trial will be carried out within a specialised multidisciplinary HCM clinic. This incorporates the expertise of specialist cardiologists and cardiac genetic counsellors. ${ }^{27}$ Patients with HCM attending these clinics at Royal Prince Alfred Hospital will be invited to attend.

\section{Eligibility criteria}

HCM probands with a genetic result ready for return are eligible. HCM probands are defined as the first person in the family to undergo genetic testing for HCM. Probands include those with and without a family history of disease provided genetic testing has been ordered. Participants must be aged 18 years or older, with sufficient written English skills as nominated by the participant. Genetic testing is performed as part of a research study, or commercial laboratory as previously published..$^{28}$ All identified variants are classified in the same manner, as per current clinical standards and guidelines. ${ }^{30}$ Recruitment commenced in November 2017 and is expected to end in November 2018. Participants will be invited to participate in the study during their routine preclinic phone call conducted as normal clinical process. Informed consent will be obtained by the cardiac genetic counsellor present at the participants clinic consultation (online supplementary material).

\section{Randomisation}

A randomised list was prepared using the Excel (Microsoft Office) 'Random' function, and study participants who consent to the study are allocated the next number on the random list. This number is linked to either control or intervention. A researcher not involved in the study performs the randomisation.

\section{Sample size and power calculations}

Prior to commencement of the study, power calculations were performed using the results from our published feasibility study. ${ }^{31}$ The primary outcome of this trial is the 


\section{My family} summary

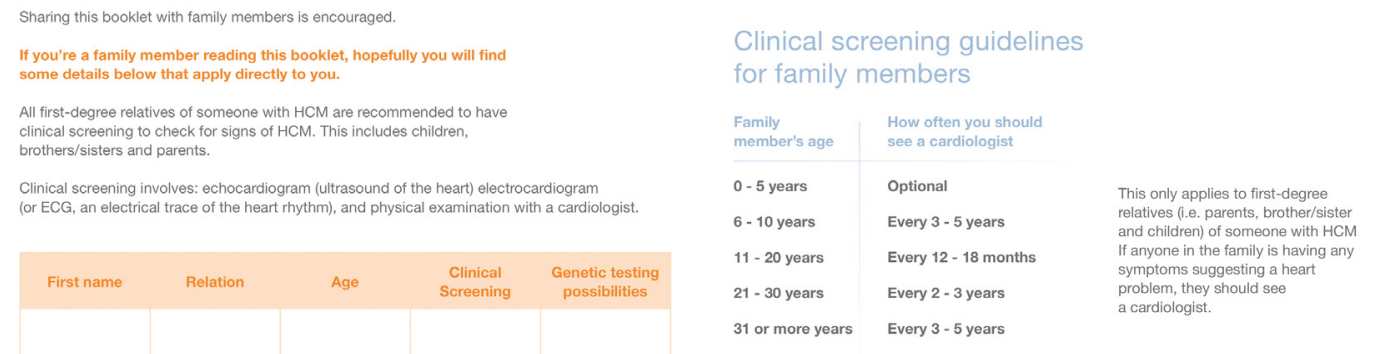

Figure 4 Example page from communication aid: family-screening guidelines.

ability and confidence of the proband to communicate genetic results to at-risk relatives. Data from the feasibility study indicated $75 \%$ of participants communicated genetic results to at-risk relatives. Assuming the control group communicates in $50 \%$ of cases, at a significance level of $5 \%$ and $80 \%$ statistical power, a sample size of $\mathrm{n}=21$ is required per group.

\section{Development of the custom communication aid}

We have developed a communication aid to assist with the delivery of genetic results to the proband and support family communication. A pilot study demonstrating feasibility and acceptability of this aid has been previously reported. ${ }^{31}$ In brief, development of the aid involved review of the literature alongside multidisciplinary meetings. Development was a multistep process and on the basis of meeting outcomes, literature review and empirical evidence from the multidisciplinary team. The aid addresses:

1. Genetic test basic background information.

2. Possible outcomes of genetic testing.

3. Overview of the process involved in classification of a genetic variant.

4. Implications for at-risk relatives including family screening recommendations.

\section{Control arm}

Those within the control arm of the study will receive their result via normal clinical practice. There are currently no evidence-based guidelines for return of comprehensive genetic test results within the multidisciplinary clinic setting. Normal clinical practice typically involves return of a genetic result either by the cardiologist or genetic counsellor. Return of the result is usually performed following clinical cardiology review, which is often the primary purpose of the consult. In the majority of cases, a genetic counsellor is present.

\section{Intervention arm}

Those randomised to the intervention arm will be allocated a separate appointment time after clinical review with their cardiologist, where they will see the cardiac genetic counsellor who will return their genetic result using the communication aid.

The communication aid covers the process of genetic testing and risk from diagnosis of HCM through to the implications of a genetic result for at-risk relatives (figure 2). There is a section in the aid under 'Results', which goes through the meaning of each category of genetic result. These include an indeterminate result (no variant identified), a variant of uncertain significance and a likely pathogenic/pathogenic result (figure 3). The genetic counsellor returning the genetic result will mark the appropriate category of result, which applies to the patient in front of them. The genetic counsellor will return the genetic result, and then go through the communication aid, referencing the individual result and specific recommendations for the rest of the family. There will be an opportunity to ask questions, and the genetic counsellor will write the specific recommendations for each family member in the box provided at the end of the communication aid (figure 4).

\section{Patient and public involvement}

Development of this research question and outcome measures were informed by clinical experience of the authors in a specialised clinic setting, as well as published research identifying gaps in communication with relatives. Specifically, there are known challenges associated with understanding and subsequent communication of 
genetic information to relatives. We have shown poor understanding, recall and communication of genetic results among HCM probands. ${ }^{72}$ Prior to implementation and development of this trial, a pilot study involving patients was conducted, incorporating patient preference and needs allowing development of both the communication aid and the study protocol. ${ }^{31}$ Results will be disseminated to patients in the form of a research participant newsletter on completion of the study. In addition, those randomised to the control arm will receive a copy of the communication aid. Patients provided written consent to participate in the study, with an understanding of the requirements of the study. These were not considered by the patients or study team to be burdensome for the patients participating in the study.

\section{DATA COLLECTION AND OUTCOMES}

Both the primary and secondary outcomes will be measured at a single time point ( 2 weeks postintervention) using a survey comprised of a number of previously published and validated scales. A number of demographic questions will also be asked within the survey. The survey will be available online via qualtrics (https://www. qualtrics.com/) with a direct link sent to participants. For those who prefer a hard copy, it will be posted with a return envelope. The survey will be sent 2 weeks after return of genetic results. Evidence regarding the most appropriate time between genetic result disclosure and family communication is lacking. However, given the risk of arrhythmia and sudden death within the inherited heart disease context, 2 weeks postresult disclosure was considered by the study team to be an appropriate time point to send the survey. ${ }^{25}$ Return of the survey is followed up on a fortnightly basis.

\section{Primary outcome}

The primary outcome of this trial is the ability and confidence of the proband to communicate genetic results to at-risk relatives. This will be measured at a single time point, administered 2 weeks after return of genetic results. Ability and confidence will be assessed by two measures and then combined into a binary outcome. The certainty subscale of the Psychological Adaptation to Genetic Information (PAGIS) scale will measure confidence with genetic knowledge. ${ }^{32}$ This subscale measures the patients' perception and confidence in their genetic knowledge, and the items from this subscale are listed in box 1 . Subsequent ability to pass this information on will be measured by the number of at-risk relatives informed of genetic results by the proband. We will average the scores from both measures to determine a final score. The calculations used to determine this cut-off are illustrated in box 2 .

In summary, we will calculate the total PAGIS certainty subscale score (denominator of 36). This will be added to the total number of relatives informed over the total number of relatives at risk. This number will

\section{Box 1 Certainty subscale of the PAGIS scale}

1. I understand how I came to have hypertrophic cardiomyopathy.

2. I understand the health risks my relatives face because of hypertrophic cardiomyopathy.

3. I feel certain that I understand the meaning of having hypertrophic cardiomyopathy.

4. I understand the chances I have of passing hypertrophic cardiomyopathy along to my children.

5. I feel that I can explain to other people what having hypertrophic cardiomyopathy means.

6. I feel confused because I have been given different explanations of what having hypertrophic cardiomyopathy means.

PAGIS, PsychologicalAdaptation to Genetic Information Scale.

then be converted to a percentage. The final score will be converted to a binary outcome of fair versus poor ability and confidence to communicate genetic results to at-risk relatives. A cut-off of $\geq 75 \%$ will be used to indicate fair communication, based on data indicating $20 \%-40 \%$ of relatives are not informed of their genetic risk. This outcome has been specifically designed for this study.

Factors that influence communication of genetic results to at-risk relatives are multidimensional. For this reason, we chose this combination approach to more broadly reflect the communication process. Many studies rely on single and linear measures of communication such as contact by relatives with genetics departments or self-reported communication with at-risk relatives only. To overcome this, we aimed to incorporate a multidimensional approach that included the probands confidence regarding their knowledge of genetics alongside the

Box 2 Primary outcome measure converted to a primary outcome

\section{Measures incorporated}

1. Certainty sub scale from PAGIS (measuring confidence).

2. Adult first-degree relatives informed of genetic risk (measuring ability).

\section{Calculation examples}

Example 1:

Certainty score from PAGIS subscale $=18 / 36=0.5$.

Relatives informed of risk $=3 / 6=0.5$

$=(0.5+0.5=1) / 2=0.5$

$=50 \%$.

Therefore, this participant falls into the 'poor communication' category of the primary outcome

\section{Example 2:}

Certainty score from PAGIS subscale $=30 / 36=0.83$.

Relatives informed of risk $=7 / 8=0.88$

$(0.88+0.83) / 2=0.86$

$=86 \%$.

Therefore, this participant falls into the 'fair communication' category of this primary outcome.

PAGIS, PsychologicalAdaptation to Genetic Information Scale. 
action linked to this knowledge, being the communication to relatives. This will aim to determine consistency between the probands confidence with genetic information against their self-reported percentage of immediate family members informed.

The certainty subscale of the PAGIS will be used to measure confidence with genetic knowledge as described above. ${ }^{32}$ Guided by grounded theory in patient perspectives of genetic counselling and the Roy Adaptation to Genetic Information Model, the 26-item PAGIS allows for evaluation of the efficacy of genetic counselling. ${ }^{32} 33$ The scale aims to incorporate the multidimensional adaptation to genetic information and comprises of five domains that include: (A) non-intrusiveness, (B) support, (C) self-worth, (D) certainty and (E) self-efficacy. ${ }^{32}$ Evidence for the utility of this scale has been published and illustrates its potential use for assessing genetic counselling interventions. ${ }^{32}$

\section{Secondary outcomes}

The survey comprises three additional scales to assess primary and secondary outcomes, a number of questions regarding communication with relatives, as well as a number of demographic questions.

Genetic knowledge will be assessed using an amended version of the Breast Cancer Genetic Counseling Knowledge Questionnaire. ${ }^{33} 34$ This scale was originally developed to assess knowledge of information typically included in genetic counselling for breast cancer. The original scale was a 27-item questionnaire including statements regarding genetics such as ' $50 \%$ (half) of your genetic information was passed down from your mother', and participants were asked if the statement was true or false. Items in the original scale were empirically derived from detailed content analysis of breast cancer genetic counselling sessions. The original scale demonstrated a high content validity with Cronbach's $\alpha=0.92$, with demonstrated ability to discriminate between patients before and after genetic counselling sessions. ${ }^{34}$ We have amended questions to reflect the HCM context, and 10 items were included.

Satisfaction with services received will be assessed using the widely used Satisfaction with Genetic Counselling Scale. ${ }^{35}$ The original questionnaire was designed to assess three dimensions of patient satisfaction: instrumental, affective and procedural. ${ }^{33} 35$ This survey will use an amended version of the 12-item short form of the survey.

The Genetic Counselling Outcome Scale will be used to assess patient-reported outcomes of genetic counselling. ${ }^{36}$ The questionnaire was designed to be used pregenetic and postgenetic counselling, though we have used it in the postcounselling setting. The authors of this scale used the construct of empowerment to summarise the patient-derived benefits from genetic counselling.

\section{Data management}

All data from the survey will be entered into Microsoft Excel. Patient identifiers will be removed with study codes allocated. The primary researcher will be blinded to treatment arm of the patient for analysis of the primary and secondary outcome data. A second senior researcher and supervisor will oversee data storage and analysis. Data will be stored in accordance with the Sydney Local Health District Ethics Review Committee and Centenary Institute.

\section{Data analysis plan}

Data will be analysed using Prism (V.7.0) and SPSS (V.23.0). We will compare the primary outcome as a binary measure between the intervention and control group. We will use chi-square analyses using $\mathrm{p}<0.05$ for statistical significance. For assessment of secondary outcomes, we will be guided by published scoring systems for the validated scales to score genetics knowledge, satisfaction with services and genetic counselling outcomes. Mean scores for each scale will be compared between the intervention and control group, and comparisons between the control and intervention group will be analysed using unpaired t-tests for continuous data and $\chi^{2}$ analysis for categorical data. Subgroup analysis will also be performed; specifically, we will compare outcomes in the study groups stratified by the genetic result (ie, causative, uncertain or indeterminate results) and compare familial and non-familial HCM probands, which has been previously shown to influence family communication practices. ${ }^{37}$

As a longer term outcome, we will systematically assess and document family communication as reported by the proband measured by phone calls at 1, 3 and 6 monthly intervals. These phone calls will also measure uptake of family screening as reported by the proband. This will be assessed separately to the primary and secondary outcomes. We will compare outcomes between the study groups stratified by the genetic result (ie, causative, uncertain or indeterminate results). In addition, we will compare outcomes between study groups stratified by those with and without a family history of HCM.

\section{ETHICS AND DISSEMINATION \\ Dissemination}

Results from this trial will be prepared as a manuscript and submitted to peer-reviewed journals for publication. In addition, it will form part of the first authors' PhD thesis. Results from the study will be submitted to international and national scientific sessions with the aim of being presented. We will make a copy of the aid available to a wider genetic audience for use in their clinical practice, and study data will be available from the authors. This will include development of an electronic form of the aid.

Acknowledgements We would like to thank Yana Smagarinsky for her assistance with developing the communication aid and Katharine Morgan for graphic design of the communication aid.

Contributors All authors contributed to the manuscript, specifically: substantial contributions to the conception or design of the work; the acquisition, analysis or interpretation of data for the work; drafting the work or revising it critically for important intellectual content; final approval of the version to be published; and agreement to be accountable for all aspects of the work in ensuring that questions related to the accuracy or integrity of any part of the work are appropriately investigated and resolved. 
Funding $C B$ is the recipient of an Australia Postgraduate Award. CS is the recipient of a National Health and Medical Research Council Practitioner Fellowship (\#1059156). $\mathrm{Jl}$ is the recipient of a National Heart Foundation of Australia Future Leader Fellowship (\#100833).

Competing interests None declared.

Patient consent Obtained.

Ethics approval All aspects of the study will be performed according to institutional human research ethics committee approval. This study has been approved by and is in strict accordance with the Sydney Local Health District Ethics Review Committee (X16-0030).

Provenance and peer review Not commissioned; externally peer reviewed.

Open access This is an open access article distributed in accordance with the Creative Commons Attribution Non Commercial (CC BY-NC 4.0) license, which permits others to distribute, remix, adapt, build upon this work non-commercially, and license their derivative works on different terms, provided the original work is properly cited, appropriate credit is given, any changes made indicated, and the use is non-commercial. See: http://creativecommons.org/licenses/by-nc/4.0/.

\section{REFERENCES}

1. Maron BJ, Maron MS, Semsarian C. Genetics of hypertrophic cardiomyopathy after 20 years: clinical perspectives. J Am Coll Cardiol 2012;60:705-15.

2. Semsarian $\mathrm{C}$, Ingles J, Maron MS, et al. New perspectives on the prevalence of hypertrophic cardiomyopathy. J Am Coll Cardiol 2015;65:1249-54.

3. Ingles J, Burns C, Barratt A, et al. Application of genetic testing in hypertrophic cardiomyopathy for preclinical disease detection. Circ Cardiovasc Genet 2015;8:852-9.

4. Resta R, Biesecker BB, Bennett RL, et al. A new definition of genetic counseling: national society of genetic counselors' task force report. $J$ Genet Couns 2006;15:77-83.

5. Semsarian $\mathrm{C}$, Ingles J. A clinical approach to genetic testing for nonspecialists. BMJ 2017;358:j4101.

6. Burns C, James C, Ingles J. Communication of genetic information to families with inherited rhythm disorders. Heart Rhythm 2018;15:780-6.

7. Burns C, McGaughran J, Davis A, et al. Factors influencing uptake of familial long QT syndrome genetic testing. Am J Med Genet $A$ 2016;170A:418-25.

8. Christiaans I, Birnie E, Bonsel GJ, et al. Uptake of genetic counselling and predictive DNA testing in hypertrophic cardiomyopathy. Eur $J$ Hum Genet 2008;16:1201-7.

9. Gaff CL, Clarke AJ, Atkinson P, et al. Process and outcome in communication of genetic information within families: a systematic review. Eur J Hum Genet 2007;15:999-1011.

10. Claes E, Evers-Kiebooms G, Boogaerts A, et al. Communication with close and distant relatives in the context of genetic testing for hereditary breast and ovarian cancer in cancer patients. Am J Med Genet A 2003;116A:11-19.

11. Barsevick AM, Montgomery SV, Ruth $\mathrm{K}$, et al. Intention to communicate BRCA1/BRCA2 genetic test results to the family. Journal of Family Psychology 2008;22:303-12.

12. Burns C, Yeates L, Spinks C, et al. Attitudes, knowledge and consequences of uncertain genetic findings in hypertrophic cardiomyopathy. Eur J Hum Genet 2017;25:809-15.

13. Patenaude AF, Tung N, Ryan PD, et al. Young adult daughters of BRCA1/2 positive mothers: what do they know about hereditary cancer and how much do they worry? Psychooncology 2013;22:2024-31.

14. Young AL, Butow PN, Vetsch J, et al. Family communication, risk perception and cancer knowledge of young adults from brca1/2 families: a systematic review. J Genet Couns 2017;26:1179-96.

15. Forrest LE, Burke J, Bacic S, et al. Increased genetic counseling support improves communication of genetic information in families. Genet Med 2008;10:167-72.
16. Fiallos K, Applegate C, Mathews DJ, et al. Choices for return of primary and secondary genomic research results of 790 members of families with Mendelian disease. Eur J Hum Genet 2017;25:530-7.

17. Forrest K, Simpson SA, Wilson BJ, et al. To tell or not to tell: barriers and facilitators in family communication about genetic risk. Clin Genet 2003;64:317-26.

18. Montgomery SV, Barsevick AM, Egleston BL, et al. Preparing individuals to communicate genetic test results to their relatives: report of a randomized control trial. Fam Cancer 2013;12:537-46

19. Chivers Seymour K, Addington-Hall J, Lucassen AM, et al. What facilitates or impedes family communication following genetic testing for cancer risk? A systematic review and meta-synthesis of primary qualitative research. J Genet Couns 2010;19:330-42.

20. Healey E, Taylor N, Greening S, et al. Quantifying family dissemination and identifying barriers to communication of risk information in Australian BRCA families. Genet Med 2017;19:1323-31.

21. Hodgson J, Metcalfe S, Gaff C, et al. Outcomes of a randomised controlled trial of a complex genetic counselling intervention to improve family communication. Eur J Hum Genet 2016;24:356-60.

22. Suthers GK, Armstrong J, McCormack J, et al. Letting the family know: balancing ethics and effectiveness when notifying relatives about genetic testing for a familial disorder. J Med Genet 2006;43:665-70.

23. Stacey $D$, Légaré $F$, Lewis $K$, et al. Decision aids for people facing health treatment or screening decisions. Cochrane Database Syst Rev 2017;4:CD001431.

24. Wakefield CE, Meiser B, Homewood J, et al. Development and pilot testing of two decision aids for individuals considering genetic testing for cancer risk. J Genet Couns 2007;16:325-39.

25. Vavolizza RD, Kalia I, Erskine Aaron K, et al. Disclosing genetic information to family members about inherited cardiac arrhythmias: an obligation or a choice? J Genet Couns 2015;24:608-15.

26. Chan AW, Tetzlaff JM, Altman DG, et al. SPIRIT 2013 statement: defining standard protocol items for clinical trials. Ann Intern Med 2013;158:200-7

27. Ingles J, Lind JM, Phongsavan P, et al. Psychosocial impact of specialized cardiac genetic clinics for hypertrophic cardiomyopathy. Genet Med 2008;10:117-20.

28. Bagnall RD, Weintraub RG, Ingles J, et al. A prospective study of sudden cardiac death among children and young adults. $N$ Engl J Med 2016;374:2441-52.

29. Burns C, Bagnall RD, Lam L, et al. Multiple gene variants in hypertrophic cardiomyopathy in the era of next-generation sequencing. Circ Cardiovasc Genet 2017;10.

30. Richards S, Aziz N, Bale S, et al. Standards and guidelines for the interpretation of sequence variants: a joint consensus recommendation of the American College of Medical Genetics and Genomics and the Association for Molecular Pathology. Genet Med 2015;17:405-23.

31. Smagarinsky Y, Burns C, Spinks C, et al. Development of a communication aid for explaining hypertrophic cardiomyopathy genetic test results. Pilot Feasibility Stud 2017;3:53.

32. Read CY, Perry DJ, Duffy ME. Design and psychometric evaluation of the psychological adaptation to genetic information scale. J Nurs Scholarsh 2005;37:203-8.

33. Kasparian NA, Wakefield CE, Meiser B. Assessment of psychosocial outcomes in genetic counseling research: an overview of available measurement scales. J Genet Couns 2007;16:693-712.

34. Erblich J, Brown K, Kim Y, et al. Development and validation of a breast cancer genetic counseling knowledge questionnaire. Patient Educ Couns 2005;56:182-91.

35. Shiloh S, Avdor O, Goodman RM. Satisfaction with genetic counseling: dimensions and measurement. Am J Med Genet 1990;37:522-9.

36. McAllister M, Wood AM, Dunn G, et al. The Genetic Counseling Outcome Scale: a new patient-reported outcome measure for clinica genetics services. Clin Genet 2011;79:413-24.

37. Ko C, Arscott P, Concannon M, et al. Genetic testing impacts the utility of prospective familial screening in hypertrophic cardiomyopathy through identification of a nonfamilial subgroup. Genet Med 2018;20. 